\title{
Recording of left atrial potentials from pulmonary artery in $\operatorname{man}^{\star}$
}

\author{
GUUNTER BREITHARDT, LUDGER SEIPEL
}

From the Medical Hospital B, University of Düsseldorf, Düsseldorf, Germany

SUMMARY The purpose of the present study was to validate the recording of left atrial activity from the pulmonary artery in man. Fifteen patients with atrial septal defect or patent foramen ovale were studied. Atrial activity was recorded simultaneously from the pulmonary artery and the high left atrium either during sinus rhythm or during paced ectopic atrial rhythm.

The results have shown a close similarity between the atrial signals recorded from the proximal (that is right-sided) high left atrium and the right pulmonary artery (overlying the vertebral column) both during sinus rhythm and paced ectopic atrial rhythm. Activity from the pulmonary arterial trunk corresponded best to signals from the lateral high left atrium. The latest activity, originating probably from the lateral left atrium, was recorded from the left pulmonary artery. However, in many cases the amplitude of the signals from the left pulmonary artery was too small to allow precise definition of the onset of atrial activity.

We conclude that recording atrial activity from the pulmonary artery is a valid approach for studying high left atrial activation if there is no direct access to the left atrium. When this technique is used in association with the recording of left atrial signals from the coronary sinus, left atrial activity can be analysed in detail.

Atrial mapping is of diagnostic significance for the analysis of the excitation sequence within the atria during atrial tachyarrhythmias and in reentry tachycardias using retrogradely conducting accessory pathways. ${ }^{1-3}$ For this purpose, techniques have been devised for recording right atrial potentials. $^{3-5}$ Direct access to the left atrium is usually difficult except for cases with a patent foramen ovale or with an atrial septal defect. Therefore, left atrial activity can usually be recorded only from the coronary sinus ${ }^{6-8}$ or from the oesophagus..$^{9-11}$

In the present study we wanted to see whether activity from the high left atrium could also be recorded from the pulmonary artery. A similar approach had previously been suggested by Kossmann et al.,4 Puech, ${ }^{7}$ Amat-y-Leon et al.,12 and Ogawa et al. ${ }^{13}$ However, these authors did not validate this approach by simultaneously recording atrial activity from the high left atrium and from the pulmonary artery.

\footnotetext{
* Partly supported by the Landesamt für Forschung, NordrheinWestfalen.

Received for publication 1 November 1979
}

\section{Patients and methods}

The recordings were done in 15 patients in the nonsedated postabsorptive state, in whom His bundle electrography was indicated for clinical reasons or in whom right heart catheterisation was performed for evaluation of an atrial septal defect. All patients had given informed written consent. Cardioactive drugs had been withdrawn before the study.

The recording techniques used in our laboratory have been described before. ${ }^{14}{ }^{15}$ For recording left atrial potentials a quadripolar electrode catheter was introduced into the high left atrium via a patent foramen ovale or an atrial septal defect. The interelectrode distance was $1.0 \mathrm{~cm}$, with the distal electrode at the tip of the catheter. The distal electrode was positioned within the high left atrium at the margin of the lateral atrial wall. Electrograms from the pulmonary artery were recorded from a bipolar electrode catheter (4 F, electrode distance $0.5 \mathrm{~cm}$; Cordis). Additionally, high right atrial potentials were recorded either by a bipolar electrode catheter or by changing the position of the quadripolar catheter from the high left atrium into the right atrial appendage. After recording 
atrial electrograms from the pulmonary artery, the bipolar catheter was withdrawn and used for recording low atrial potentials at the orifice of the inferior vena cava and of low septal activation from the His bundle recording site. All catheters were connected to an eight-channel direct writing recorder (Mingograph, Siemens-Elema) via a switchbox with isolated inputs.

In 10 patients (group 1), the following positions within the pulmonary artery were used for recording (Fig. 1): the pulmonary trunk (position 1), the right pulmonary artery overlying the vertebral column in the posteroanterior projection (position 2), an additional site within the right pulmonary artery at the lateral margin of the right atrium (peripheral right pulmonary artery, position 3), and from the left pulmonary artery (position 4). The onset of the $P$ wave in lead II was used as a time reference.

In five patients (group 2), signals from the right pulmonary artery and the high left atrium were recorded simultaneously during both spontaneous

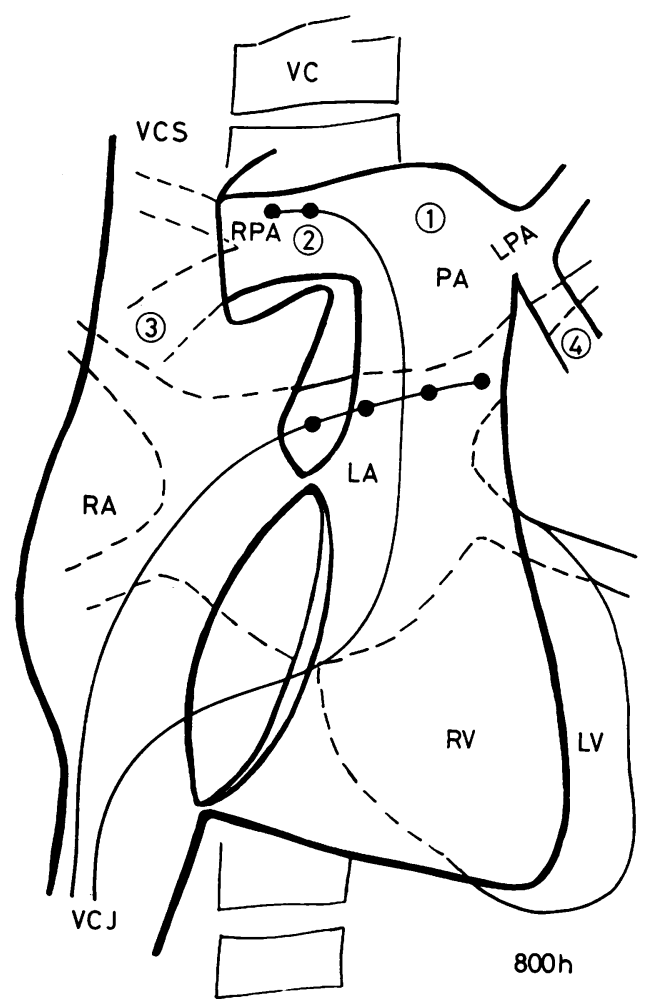

Fig. 1 Schematic drawing of the heart showing the recording sites within the high left atrium and the pulmonary artery (PA). The electrodes of the catheters are indicated by large dots. For further details see method section. sinus rhythm and paced rhythm from the low lateral right atrium.

In all cases at least five consecutive cycles were measured from which the mean values were derived. Statistical analysis was by Student's t test for paired data.

\section{Results}

Fifteen patients were studied (mean age 36.0 years, range 16 to 57 years). The clinical diagnoses and the intervals in the surface electrocardiogram are presented in Table 1.

In 10 cases (group 1, Table 2), an attempt was made to record atrial signals from the pulmonary trunk and-with one exception-from both right and left pulmonary arteries. The catheter could be manipulated into the right pulmonary artery in all cases. In three cases it was not possible to advance the catheter into the left pulmonary artery and in one case no attempt was made to reach it. In two cases the amplitudes were too low to record atrial activity from the left pulmonary artery. In two other cases the electrode catheter fell back into the right ventricle when withdrawing it from the right pulmonary artery; no further attempt was made to advance it again into the pulmonary trunk. In some cases, the atrial signals were too low for a clear distinction of the onset of atrial activity (Table 2).

Fig. 2 shows typical examples of recordings of

Table 1 Clinical diagnoses, age, sex, and intervals in surface electrocardiogram in patients studied

\begin{tabular}{|c|c|c|c|c|c|}
\hline $\begin{array}{l}\text { Case } \\
\text { no. }\end{array}$ & $\begin{array}{l}\text { Age/Sex } \\
(y)\end{array}$ & Diagnosis & $P$ & $P Q$ & $Q R S$ \\
\hline 1 & $36 / F$ & $\begin{array}{l}\text { LBBB, patent } \\
\text { foramen ovale }\end{array}$ & 100 & 220 & 180 \\
\hline 2 & $27 / F$ & ASD (small) & 110 & 180 & 80 \\
\hline 3 & $40 / M$ & ASD (large) & 120 & 200 & 100 \\
\hline 4 & $16 / F$ & ASD (small) & 80 & 170 & 85 \\
\hline 5 & $17 / F$ & ASD (small) & 90 & 140 & 85 \\
\hline 6 & $\begin{array}{l}32 / \mathrm{M} \\
22 / \mathrm{F}\end{array}$ & $\begin{array}{l}\text { ASD (small) } \\
\text { Patent foramen }\end{array}$ & 100 & 170 & 120 \\
\hline & & ovale, VSD & 90 & 150 & 75 \\
\hline 8 & $40 / M$ & $\begin{array}{l}\text { CCM, VT, patent } \\
\text { foramen ovale }\end{array}$ & 100 & 230 & 90 \\
\hline 9 & 46/F & ASD (large) & 110 & 180 & 100 \\
\hline 10 & $57 / F$ & ASD (large) & 110 & 150 & 120 \\
\hline 11 & $38 / F$ & Sinus bradycardia & 90 & 160 & 90 \\
\hline 12 & $29 / F$ & $\begin{array}{l}\text { Ventricular } \\
\text { tachycardia }\end{array}$ & 90 & 150 & 70 \\
\hline $\begin{array}{l}13 \\
14\end{array}$ & $\begin{array}{l}32 / \mathrm{F} \\
53 / \mathrm{M}\end{array}$ & $\begin{array}{l}\text { ASD (small) } \\
\text { Coronary artery }\end{array}$ & 100 & 180 & 70 \\
\hline & & & 80 & 170 & 90 \\
\hline \multirow[t]{2}{*}{15} & $34 / F$ & Atrial tachycardia & 120 & 170 & 90 \\
\hline & $\begin{array}{l}34 \cdot 6 \pm \\
11 \cdot 8 \text { years }\end{array}$ & & $\begin{array}{l}99 \cdot 3 \pm \\
12 \cdot 8 \mathrm{~ms}\end{array}$ & $\begin{array}{c}174 \cdot 7 \pm \\
25 \cdot 6 \mathrm{~ms}\end{array}$ & $\begin{array}{l}96 \cdot 3 \pm \\
27.6 \mathrm{~ms}\end{array}$ \\
\hline
\end{tabular}

Abbreviations: ASD, atrial septal defect; VSD, ventricular septal defect; LBBB, left bundle-branch block; VT, ventricular tachycardia; CCM, congestive cardiomyopathy. 
Table 2 Sequence of atrial activation

\begin{tabular}{|c|c|c|c|c|c|c|c|c|c|}
\hline Case no. & $H R A$ & $H L A_{\text {prox }}$ & $H L A_{\text {distal }}$ & $R P A_{\text {per. }}$ & $R P A_{v c}$ & $P A_{\text {trunk }}$ & $L P A$ & $A$ & $V C_{i n f}$ \\
\hline 1 & 0 & 45 & 55 & - & 50 & - & - & 35 & - \\
\hline 2 & 0 & 25 & 55 & 28 & 33 & 50 & 56 & 40 & 43 \\
\hline 3 & 5 & 30 & 53 & - & 39 & LA & - & 50 & - \\
\hline 4 & 20 & 38 & 55 & 30 & 35 & LA & LA & 30 & - \\
\hline 5 & 0 & 54 & 56 & 28 & 24 & LA & 54 & 44 & 20 \\
\hline 6 & 30 & 22 & 38 & LA & 49 & 55 & 68 & 50 & 57 \\
\hline 7 & 25 & 27 & 46 & - & 14 & 42 & - & 40 & 40 \\
\hline 8 & 0 & 30 & 55 & - & 25 & 二 & - & 45 & - \\
\hline 9 & 5 & 49 & 66 & 10 & 29 & LA & 62 & 30 & 35 \\
\hline \multirow[t]{2}{*}{10} & 23 & 42 & 60 & - & LA & 54 & LA & 35 & 40 \\
\hline & $\begin{array}{c}10 \cdot 8 \pm \\
12 \cdot 2\end{array}$ & $\begin{array}{l}36 \cdot 2 \pm \\
11 \cdot 0 \\
\text { (except for } \\
\quad \text { case } 10: \\
35 \cdot 6 \pm 11 \cdot 4 \text { ) }\end{array}$ & $\begin{array}{l}53 \cdot 9 \pm \\
7 \cdot 5\end{array}$ & $\begin{array}{l}\mathrm{n}=4 \\
24 \cdot 0 \pm \\
9 \cdot 4\end{array}$ & $\begin{array}{l}\mathbf{n}=9 \\
33 \cdot 1 \pm \\
11 \cdot 8\end{array}$ & $\begin{array}{l}n=4 \\
50 \cdot 3 \pm \\
5 \cdot 9\end{array}$ & $\begin{array}{l}\mathrm{n}=4 \\
60 \cdot 0 \pm \\
6 \cdot 3\end{array}$ & $\begin{array}{l}39 \cdot 9 \pm \\
7 \cdot 4\end{array}$ & $\begin{array}{l}\mathbf{n}=6 \\
39 \cdot 2 \pm \\
12 \cdot 0\end{array}$ \\
\hline
\end{tabular}

All intervals in $\mathrm{ms}$; the onset of the $\mathrm{P}$ wave in lead II was used as time reference.

Abbreviations: HRA, high right atrium; HLA prox, high left atrium proximal to the HRA; HLAdistal, high left atrium distal to the HRA; RPA peripheral, right pulmonary artery, peripheral site (position 3 in Fig. 1);

$\mathbf{R P A}_{\mathrm{vc}}$, right pulmonary artery in line with the vertebral column (vc) (position 2 in Fig. 1); PA trunk, pulmonary artery trunk; LPA, left pulmonary artery; $A$, low septal atrial electrogram; $V_{\text {inf }}$, low atrial electrogram at the orifice of the vena cava inferior; LA, low amplitude atrial signal not suitable for measuring onset of activation; -, this site was either not reached or no attempt was made to reach it.

atrial activity from various sites within the pulmonary artery, comparing it with the activity that was recorded directly in the high left atrium.

In Table 2, the results in the individual cases are presented. The high right atrium was activated at $10 \cdot 8 \pm 12.2 \mathrm{~ms}$ (mean \pm SD) after the onset of the $P$ wave in lead II. Activity then spread to the right side of the high left atrium which was activated at $36.2 \pm 11.0 \mathrm{~ms}$, and to the lateral high left atrium which was activated at $53.9 \pm 7.5 \mathrm{~ms}$ after the onset of the $P$ wave in lead II. The signal from the right pulmonary artery overlying the vertebral column (position 2 in Fig. 1) coincided best with the activation time in the rightward part of the high left atrium, whereas the signal from the pulmonary trunk coincided with the lateral high left atrium. Mean activation time in the four cases in whom atrial activity could be recorded from both sites was $50.3 \pm 5.9 \mathrm{~ms}$ (pulmonary trunk) and 53.8 \pm $11.6 \mathrm{~ms}$ (lateral high left atrium). The atrial signal recorded from the left pulmonary artery was recorded at $60 \cdot 0 \pm 6.3 \mathrm{~ms}(\mathrm{n}=4)$ after the onset of the $P$ wave. For the four cases in whom atrial activity was also recorded from a more peripheral position in the right pulmonary artery, the atrial signal appeared at $24 \cdot 0 \pm 9 \cdot 4 \mathrm{~ms}$.

The results in group 2 patients, in whom right pulmonary artery signals were compared with those from the high left atrium during sinus rhythm and a paced ectopic atrial rhythm, are presented in Table 3. An example of this type of recording is shown in Fig. 3. The difference between both signals ranged between -5 and $20 \mathrm{~ms}$ during sinus rhythm and between -2 and $25 \mathrm{~ms}$ during an ectopic atrial rhythm. The mean absolute differences between both signals during sinus rhythm and an ectopic atrial rhythm were not different.

\section{Discussion}

Sites used hitherto for endocardial atrial mapping in man were confined to the right atrium and the coronary sinus. Only occasionally could left atrial activity be recorded via a patent foramen ovale or an atrial septal defect. Several authors have reported their results on the recording of left atrial potentials from various sites outside the left atrium. ${ }^{4} 91316$ Kossman et al. ${ }^{4}$ recorded potentials from the pulmonary trunk, which they attributed to the left atrium on the basis of the close anatomical relation between the pulmonary trunk and the high left atrium. Similarly, Puech, ${ }^{7}$ and Latour and Puech ${ }^{8}$ used the pulmonary artery for recording left atrial activity. Recently, this approach was again suggested by Amat-y-Leon et al. ${ }^{12}$ in a case report. In this case, left atrial activity was recorded simultaneously with the atrial electrogram from the pulmonary trunk; activation occurred at the end of the $P$ wave 
$80 \mathrm{~ms}$ after that in the high right atrium. Ogawa et al. ${ }^{13}$ reported a close correlation between action potentials from Bachmann's bundle and the right pulmonary artery in experimental canine studies. In these studies, the atrial signals recorded in the right pulmonary artery coincided exactly with the activation of Bachmann's bundle in nine experiments and in seven other experiments the difference was less than $10 \mathrm{~ms}^{13}$

The present study was directed towards validating this approach in man. Apart from a single case report, ${ }^{13}$ previous studies have not recorded left atrial electrogram simultaneously ${ }^{14}$ with that of the pulmonary artery. Therefore, we studied the relation between signals from the pulmonary arteries and the high left atrium.

The results have shown a close correlation between the atrial signals from the right pulmonary artery (overlying the vertebral column in the posteroanterior projection) and the high left atrial activity recorded from the rightward portion of the

Table 3 Differences between activities from right pulmonary artery and high left atrium (that is RPA minus HLA) during sinus rhythm (left panel), and a paced rhythm from the lateral wall of the right atrium (right panel)

\begin{tabular}{lll}
\hline Case no. & $\begin{array}{l}\text { Sinus rhythm } \\
(\mathrm{ms})\end{array}$ & $\begin{array}{l}\text { Ectopic atrial } \\
\text { rhythm (ms) }\end{array}$ \\
\hline 1 & 10 & -2 \\
2 & 20 & 10 \\
3 & -5 & 10 \\
4 & 0 & 7 \\
5 & 15 & 25 \\
\hline & $8 \cdot 0 \pm 10.4$ & $10.0 \pm 9.7$ \\
\hline
\end{tabular}

Fig. 2 Top: Original recording in case 2 from the high right atrium (HRA), the high left atrium ( $H L A)$, and from three recording sites in the pulmonary artery. $H R A_{1}$ and $H R A_{2}$ were recorded from the proximal and distal pair of electrodes of a quadripolar electrode catheter introduced into the right atrial appendage.

$H L A_{\text {prox }}$ and $H L A_{\text {dist }}$ are two recording sites within the high left atrium from the proximal and distal pair of electrodes of a quadripolar catheter (see Fig. 1). $R P A_{V C}$ represents a signal from the right pulmonary artery overlying the vertebral column; $P A T R$ stands for pulmonary artery trunk.

Bottom: Case 6. The recording sites from the high left atrium (HLA) were similar to the one in the top panel. Recordings from the pulmonary artery were made from the right pulmonary artery (RPA), the pulmonary artery trunk (PAT), and the left pulmonary (LPA).

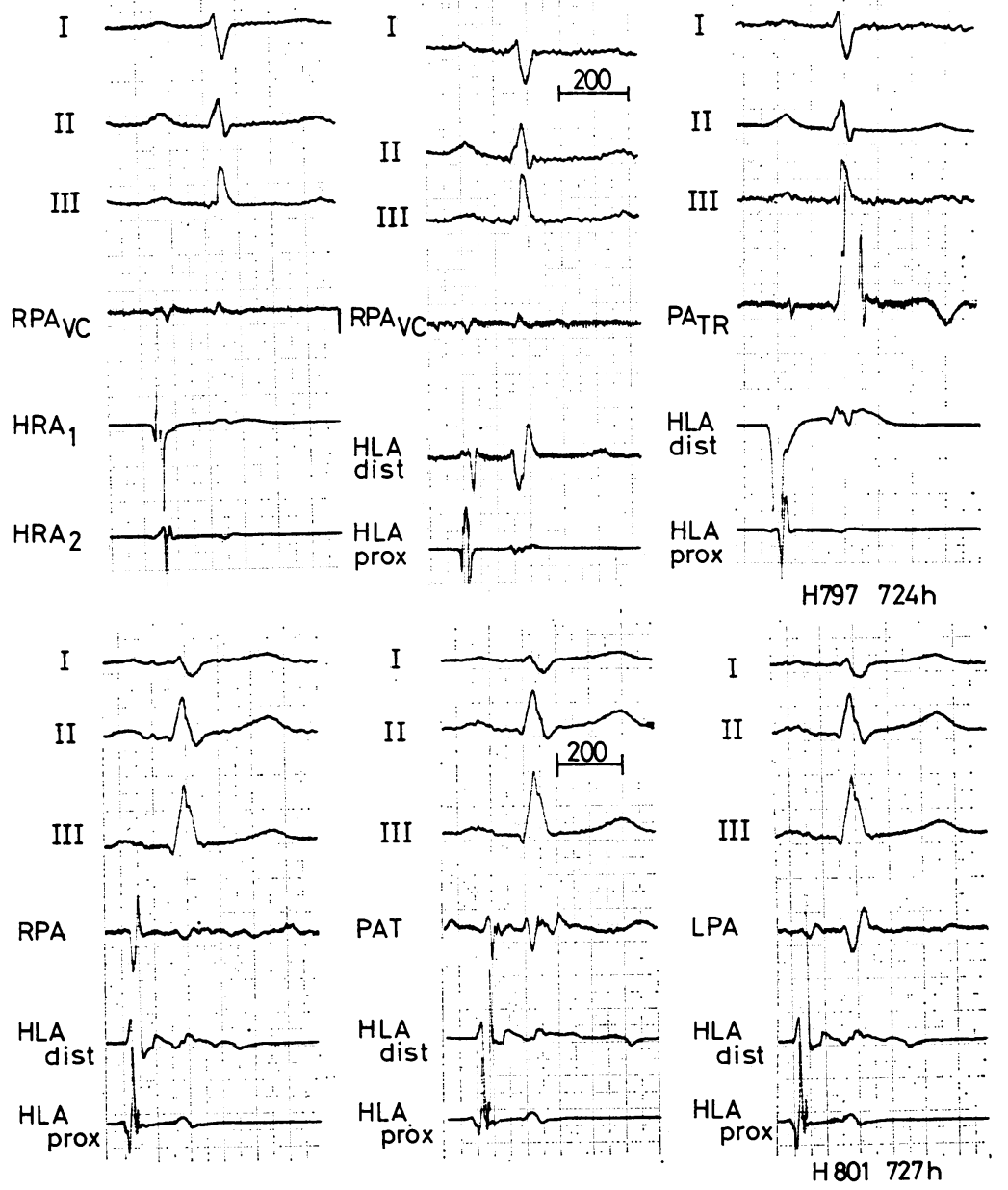




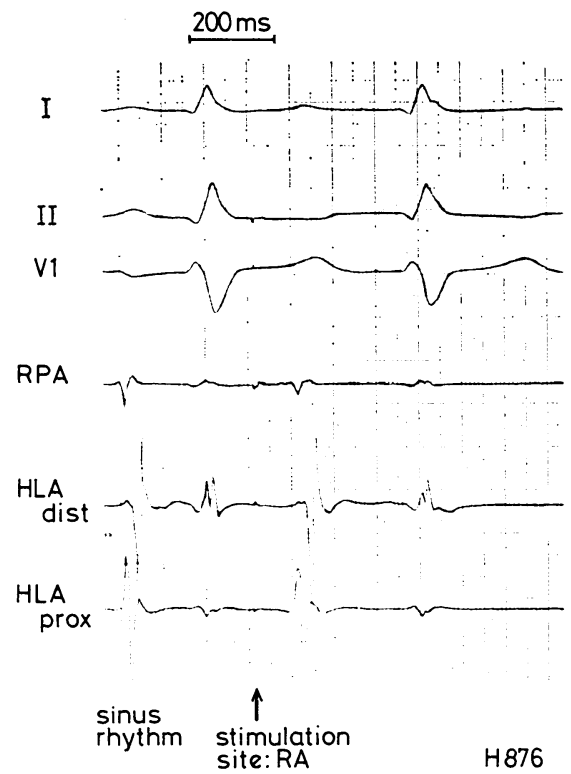

Fig. 3 Original recording during sinus rhythm (first cycle) and after a premature atrial depolarisation that was introduced in the low lateral right atrium. Leads I, $I I$, and V1 as well as three intracardiac leads are shown (for abbreviations, refer to Fig. 2). There is a close correlation in timing between the atrial activity recorded from the right pulmonary artery and the proximal (that is right-sided) left atrium during sinus rhythm and during ectopic atrial rhythm.

high left atrium (Table 2). The mean difference between both sites was $3.1 \mathrm{~ms}$, which is not significant. In the individual case, however, the difference between both sites of recording was more pronounced, ranging between 3 and $30 \mathrm{~ms}$.

The simultaneous inscription of the electrograms from the pulmonary artery and the left atrium during sinus rhythm does not necessarily mean that the electrode in the right pulmonary artery is indeed recording high left artial activity. Both signals could well be generated via different pathways during sinus rhythm, occurring simultaneously only by chance. Therefore, both signals were also recorded during a paced ectopic atrial rhythm (Table 3, Fig. 3). They retained similar timing even when the origin of the rhythm was moved to the low lateral right atrium.

The amplitude of atrial signals recorded from the left pulmonary artery or the pulmonary trunk was sometimes inadequate for analysis (Table 2). In those patients in whom the signals were sufficiently large, the activity from the pulmonary trunk occurred $17 \cdot 2 \mathrm{~ms}$ later on average than the activity in the right pulmonary artery (overlying the vertebral column). These signals correlated closely with the activation of the lateral parts of the high left atrium as recorded from the distal pair of electrodes of the quadripolar catheter. The signals from the left pulmonary artery were $9.7 \mathrm{~ms}$ later on average, than those from the pulmonary trunk. They represented the latest left atrial activation sites in our study.

Our results concerning the activation time within the right pulmonary artery are at variance with those reported by Puech. ${ }^{7} \mathrm{He}$ recorded the atrial activity at the origin of the right pulmonary artery, which is between our recording positions 1 and 2 (Fig. 1), 45 to $60 \mathrm{~ms}$ after the origin of the $P$ wave, whereas in our study this signal occurred 33.1 to $50.3 \mathrm{~ms}$ afterwards. Furthermore, in his study the left pulmonary artery signals appeared after 75 to $90 \mathrm{~ms}$ (average $66 \mathrm{~ms}$ in our study). These differences might be the result of different sites of recording and of different degrees of atrial disease (as patients and not normal persons were studied). In our study in man, the differences in the activation times from the pulmonary artery and the high left atrium were much greater than in the experimental study by Ogawa et al. ${ }^{13}$ This is probably because the exact site of recording could be less well defined than in an experimental model. Above all, our high left atrial signal does not represent exactly the activity from Bachmann's bundle as in the study by Ogawa et al. ${ }^{13}$ but rather from ordinary atrial myocardium. Nevertheless, the right pulmonary artery seems to be a suitable site for recording proximal high left atrial activation if no other access to the left atrium is available.

Another possibility of recording left atrial activity is from the oesophagus. ${ }^{9-11} 1718$ Though it is a safe procedure, it is not as convenient for most patients as is the introduction of a catheter using the percutaneous approach. Furthermore, the isolated recording of left atrial potentials from the oesophagus without further recording sites and without the possibility of stimulating the atria does not yield sufficient information in most cases with complex arrhythmias. Additionally, introduction of an electrode catheter into the oesophagus may stimulate vagal reflexes which might influence the arrhythmia to be recorded and the electrophysiological indices of the atria and of the atrioventricular conduction system.

This study has validated the recording of left atrial signals from the pulmonary artery in man. It is therefore an extension of former studies which have suggested this approach. ${ }^{412}$ The technique might be helpful for further delineating atrial activation sequence in cases with so-called sinus 
node re-entry. Using right atrial mapping, we were able to show that in these cases the atrial activation sequence during echo beats is similar to that of spontaneous sinus rhythm ${ }^{3}$; but we could not exclude the possibility that Bachmann's bundle rather than the high right atrium was the site of reentry. The distinction is now possible by recording high left atrial potentials from the pulmonary artery. This may lead to a better understanding of the mechanisms of so-called sinus node re-entry. The method may also help to define the site of origin of ectopic atrial rhythms in man especially when used in association with recordings from the coronary sinus, for left atrial activation can be analysed in more detail both in anterograde and retrograde directions.

\section{References}

${ }^{1}$ Wellens HJJ, Durrer D. Patterns of ventriculo-atrial conduction in the Wolff-Parkinson-White syndrome. Circulation 1974; 49: 22-31.

${ }^{2}$ Curry PVL, Krikler DM. Paroxysmal reciprocating sinus tachycardia. In: Kulbertus HE, ed. Re-entrant arrhythmias. Mechanisms and treatment. Lancaster: MTP Press, 1977: 39-62.

${ }^{3}$ Breithardt G, Seipel L, Sequence of atrial activation in patients with atrial echo beats. In: Bonke FIM, ed. The sinus node, structure, function and clinical relevance. The Hague, Boston, London: Martinus Nijhoff, 1978: 389-408.

"Kossmann CE, Berger AR, Rader B, Brumlik J, Briller SA, Donelly JH. Intracardiac and intravascular potentials resulting from electrical activity of the normal human heart. Circulation 1950; 2: 10-30.

${ }^{5}$ Waldo AL, MacLean WAH, Karp RB, Kouchoukos T, James JN. Sequence of retrograde atrial activation of the human heart. Correlation with $\mathbf{P}$ wave polarity. Br Heart F 1977; 39: 634-40.

'Levine HD, Goodale WT. Studies in intracardiac electrocardiography in man. IV. Potential variations in the coronary venous system. Circulation 1950; 2: 48-59.

'Puech P. L'activité électrique auriculaire normale et pathologique. Paris: Masson \& Cie, 1956.
${ }^{8}$ Latour H, Puech P. Electrocardiographie endocavitaire. Paris: Masson \& Cie, 1957.

'Cremer M. Über die direkte Ableitung der Aktionsströme des menschlichen Herzens vom Oesophagus und über das Elektrokardiogramm des Fötus. Münch Med Wochenschr 1906; 53: 811-3.

${ }^{10}$ Spühler O. Das Oesophagus-Elektrokardiogramm. Z klin Med 1938; 134: 671-97.

${ }^{11}$ Franke H. Zur Beurteilung der Vorhofspotentiale im Ösophagus- und intrakardialen Ekg. Verh Dtsch Ges Kreislaufforsch 1952; 18: 172-9.

${ }^{12}$ Amat-y-Leon F, Deedwania P, Miller RH, Dhingra RC, Rosen KM. A new approach for indirect recording of anterior left atrial activation in man. Am Heart $\mathcal{F}$ 1977; 93: 408-10.

${ }^{13}$ Ogawa S, Dreifus LS, Kitchen JG III, Shenoy PN, Osmick MJ. Catheter recording of Bachmann's bundle activation from the right pulmonary artery. A new technique for atrial mapping and the study of supraventricular tachycardia. $A m$ f Cardiol 1978; 41: 1089-96.

${ }^{14}$ Breithardt G, Seipel L, Loogen F. Sinus node recovery time and calculated sinoatrial conduction time in normal subjects and patients with sinus node dysfunction. Circulation 1977; 56: 43-50.

${ }^{15}$ Seipel L, Breithardt G, Leuner Ch. Programmed atrial stimulation used for the calculation of sino-atrial conduction time (SACT) in man. In: Bonke FIM, ed. The sinus node-structure, function and clinical relevance. The Hague, Boston, London: Martinus Nijhoff, 1978; 36-45.

16Amat-y-Leon F, Dhingra RC, Wu D, Denes P, Wyndham C, Rosen KM. Catheter mapping of retrograde atrial activation. Observation during ventricular pacing and $A V$ nodal re-entrant paroxysmal tachycardia. Br Heart $\mathcal{f}$ 1976; 38: 355-62.

${ }^{17}$ Wenger R, Wick E. Das Oesophaguselektrokardiogramm bei angeborenen Anomalien des Herzens und der großen Gefäße. Arch Kreislaufforsch 1951 ; 17: 24663.

${ }^{18}$ Enselberg $\mathrm{CD}$. The oesophageal electrocardiogram in the study of atrial activity and cardiac arrbythmias. Am Heart f 1951; 41 : 382-409.

Requests for reprints to Dr G Breithardt, Medizinische Klinik und Poliklinik, Klinik B, Universität, Moorenstrasse 5, D 4000 Düsseldorf, Germany. 